\title{
A Comparison of Spinal Anesthesia with Levobupivacaine and Hyperbaric Bupivacaine for Cesarean Sections: A Randomized Trial
}

\author{
Gulen Guler, Gokhan Cakir, Ayşe Ulgey, Fatih Ugur, Cihangir Bicer, Isın Gunes, Adem Boyaci
}

Department of Anesthesiology, Medical Faculty, Erciyes University, Kayseri, Turkey.

Email: "gulen@erciyes.edu.tr

Received February $28^{\text {th }}, 2012$; revised April $2^{\text {nd }}, 2012$; accepted April $28^{\text {th }}, 2012$

\begin{abstract}
Purpose: Levobupivacaine showed a lower risk of cardiovascular and central nervous system (CNS) toxicity than bupivacaine which is the most popular local anesthetic agent in obstetric practice. The aim of this study was to investigate the clinical efficacy of levobupivacaine compared with hyperbaric bupivacaine for spinal anesthesia for cesarean section. Methods: 60 pregnant women in ASA I - II group scheduled to have elective cesarean operation were allocated into the study. Patients were randomly divided into two groups. The combinations $10 \mathrm{mg}$ levobupivacaine $(0.5 \%)+$ fentanyl $(15 \mu \mathrm{cg})$ for Group LF $(\mathrm{n}=30)$ patients, $10 \mathrm{mg}$ hyperbaric bupivacaine $(0.5 \%)+$ fentanyl $(15 \mu \mathrm{cg})$ for BF $(\mathrm{n}=$ 30) patients were intrathecally administrated a total of $2.3 \mathrm{cc}$. Sensory and motor block characteristics of the groups were assessed with pinprick and Bromage scale; observed hemodynamic changes and side effects were recorded. Results: The time to reach maximum dermatome for the sensory block, time to regression by two dermatomes and time to regress to T12 dermatome was found to be significantly long in Group BF. It was observed that in Group BF, the evolution of the motor block was faster and lasted longer. Whereas hypotension, bradycardia and nausea were less in Group LF, the need for ephedrine was higher in Group BF $(p<0.05)$. Conclusion: Since motor block time is shorter, and side effects like hypotension, bradycardia and nausea are less, the combination of levobupivacaine + fentanyl can be a good alternative in cesarean sections.
\end{abstract}

Keywords: Spinal Anesthesia; Levobupivacaine; Bupivacaine; Fentanyl; Cesarean Section

\section{Introduction}

Spinal anesthesia has a popular technique for caesarean delivery. Hyperbaric bupivacaine in $8 \%$ glucose is often used. Plain, or glucose-free, bupivacaine has been frequently referred to as "isobaric" in the literature, even after Blomqvist and Nilsson [1] demonstrated its hypobaricity. More recently, several studies have confirmed that plain bupivacaine is indeed hypobaric in comparison with human CSF [2-4]. Clinically, this manifests as an unpredictable median sensory block height with a large inter-individual spread and is occasionally associated with block failure when the spinal block has not spread high enough for surgery $[5,6]$. For this reason, hyperbaric bupivacaine is favored in obstetric anesthesia. Although hyperbaric local anesthetic solutions have a remarkable record of safety, their use is not totally without risk [7-9]. To prevent unilateral or saddle blocks, patients should move from the lateral or sitting position rapidly and after mobilization of the patients, extension or early return of

${ }^{*}$ Corresponding author. the block may be seen. Hyperbaric solutions may couse sudden cardiac arrest after spinal anesthesia because of the extension of the sympathetic block $[10,11]$. The use of truly isobaric solutions may prove less sensitive to position issues. Hyperbaric solutions may cause hypotension or bradycardia after mobilization, isobaric solutions are favored with respect to their less sensitive to position issues properties [12].

Levobupivacaine is the pure S (-) enantiomer of racemic bupivacaine but is less toxic to the heart and CNS $[13,14]$. The plain levobupivacaine has been shown to be truly isobaric with respect to CSF of pregnant women [4, 15]. Its use in this setting may there offer special advantages because this property may translate to a more predictable spread.

In this randomized, double-blind study, we evaluated the influence of levobupivacaine on the quality of the block and the incidence of side effects, particularly hypotension and compared with clinic effect of hyperbaric bupivacaine in spinal anesthesia for cesarean sections. 


\section{Methods}

After institutional ethical approval and informed consent were obtained, 60 women scheduled for elective Caesarean delivery, at more than 37 weeks' gestation, ASA physical status class I or II, were enrolled into this prospective randomized, double-blind study.

Patients refusing regional anesthesia, having contraindications to spinal anesthesia, those with a body weight over $100 \mathrm{~kg}$, shorter than $1.50 \mathrm{~cm}$ and taller than 1.75 , those who received medications other than perinatal vitamin and iron preparations, having systemic diseases, expectant mothers with fetal anomaly, placenta previa, ablation placenta were excluded from the study.

Following application of routine monitors (noninvasive BP measurement, electrocardiography, and pulse oximetry) and insertion of a peripheral $20 \mathrm{G}$ i.v cannula, a rapid infusion of lactated Ringer's solution $10 \mathrm{ml} / \mathrm{kg}$ was administered. Baseline systolic BP and heard rate were calculated as the mean of the three recordings. Patients were placed in the sitting position. After disinfecting the skin and infiltrating with $2 \%$ lidocaine, lumbar puncture was performed at the L3-4 interspace using a 25-gauge Quincke point needle. Patients were randomly divided into two groups. For Group LF $(\mathrm{n}=30) ; 10 \mathrm{mgr} 0.5 \%(2$ $\mathrm{ml}$ ) levobupivacaine (chirocaine flacon $0.5 \% 10 \mathrm{ml}$ injection solution, Abbott, USA $)+15 \mu \mathrm{cg}(0.3 \mathrm{ml})$ fentanyl (Janssen-Cilag), for group BF $(\mathrm{n}=30) ; 10 \mathrm{mgr} 0.5 \%(2$ $\mathrm{ml})$ bupivacaine (marcaine spinal heavy $0.5 \%$ Abbott) + $15 \mu \mathrm{cg}(0.3 \mathrm{ml})$ fentanyl, being a total of $2.3 \mathrm{cc}$, administered intrathecally within some 10 seconds. Subsequently, patients were turned to a $15^{\circ}-20^{\circ}$ left lateral supine position. Oxygen $4 \mathrm{~L} / \mathrm{min}$ was administered via a facial mask. The sensory level of spinal anesthesia was assessed bilaterally in the anterior axillary line by pinprick, using a short beveled $25 \mathrm{G}$ needle, and was recorded at baseline prior to spinal injection, then every minute for the first 15 min after injection, and every five minutes for the next $30 \mathrm{~min}$, and at $45 \mathrm{~min}$. Blood pressure, heart rate, and the extent of motor block were recorded at the same measurement intervals. Permission to perform operation was given once a $T_{4}-T_{6}$ level had been achieved. Considering the time of intrathecal injection as time zero, the time to onset of sensory block, the time taken to reach maximum sensory block level, the time to regression of two dermatomes of the sensory block, the duration of the regression of the sensory block level to T12 from the maximum level were recorded. The level of motor block was assessed with modified Bromage scale $(0=$ no paralysis, able to flex hips/knees/ankles; $1=$ able to move knees, unable to raise extended legs; 2 = able to flex ankles, unable to flex knees; 3 = unable to move any part of the lower limp). The time to onset of motor block, the time to reach Bromage 3 and the time of complete disappearance were recorded.

Bradycardia was defined as pulse rate $<50 \mathrm{bpm}$, and it was treated with $0.5 \mathrm{mg}$ IV atropine.

IV boluses of 5 - $10 \mathrm{mg}$ ephedrine and additional IV fluids were administered to treat hypotension, which was defined as systolic blood pressure below $100 \mathrm{~mm} \mathrm{Hg}$ or a decrease systolic pressure of $>25 \%$ from baseline value. The amount of ephedrine used for each patient was recorded. Whether there was a need for intraoperative analgesia and time to first analgesic requirement in the postoperative period were recorded and the planned treatment included incremental $25 \mu \mathrm{g}$ boluses of IV fentanyl, or general anesthesia. Intraoperative and postoperative nausea and vomiting, and other side-effects were recorded.

The calculation of the required sample size was based on mean and standard deviation of complete regression of spinal block after anesthesia with bupivacaine and levobupivacaine reported in previous investigation (10, 11): 30 patients per group were required to detect a 20 min difference in time for complete regression of spinal anesthesia with an expected effect size to standard deviation ratio of 0.9 accepting a two-tailed $\alpha$ error of $5 \%$ and a $\beta$ error of $20 \%$. Statistical assessment of the data was carried out using the statistical software SPSS 15 for Windows 15 . Shapiro-Wilks normality test was applied to see whether the data distribution was normal. For the variables that showed a normal distribution of inter group comparisons, independent two-sample t-test was used, for the variables, which did not show normal distribution, the Mann-Whitney U test was used. Within-group comparisons in repeated measurements were performed with the variance analysis. Comparisons between two qualitative variables were performed with Pearson's chi-square test. $p$ value $<0.05$ was considered to be statistically significant.

\section{Results}

There has been no statistical difference between groups in terms of their demographic characteristics and the duration of the operation (Table 1). During the study period only in one case we experienced technical difficulty and could not perform spinal anesthesia. We gave general anesthesia to the patient and the case was excluded from the study. Both groups had achieved sufficient level of anesthesia and intraoperative analgesia and did not require additional analgesics.

The onset of sensory block and the time for the sensory block to reach $\mathrm{T}_{10}$ was similar in both groups ( $\mathrm{p}$ $>0.05)$. The time taken for the sensory block to reach maximum level was shorter in Group LF and its maxi- 
Table 1. Demographic data.

\begin{tabular}{lcc}
\hline & \multicolumn{2}{c}{ Groups } \\
\cline { 2 - 3 } & Group LF $(\mathrm{n}=30)$ & Group BF $(\mathrm{n}=30)$ \\
\hline Age (yr) & $28.7 \pm 4.29$ & $29.2 \pm 4.31$ \\
Height (m) & $1.62 \pm 0.04$ & $1.61 \pm 0.03$ \\
Weight (kg) & $75.9 \pm 9.45$ & $79.3 \pm 8.80$ \\
Number of deliveries & $1.90 \pm 1.02$ & $2.66 \pm 1.32$ \\
Gestation (week) & $38.53 \pm 0.57$ & $39.1 \pm 0.40$ \\
Surgical time (min) & $45.16 \pm 6.76$ & $43.7 \pm 4.24$ \\
\hline
\end{tabular}

Results expressed as mean \pm SD when applicable. $p<0.05=$ statistically significant.

mum sensory block level was lower $(\mathrm{p}<0.05)$.

The time to regression by two dermatomes for the sensory block and its regression time to $\mathrm{T}_{12}$ were longer in Group BF $(\mathrm{p}<0.05)$ (Table 2).

The time to onset of motor block in Group BF was shorter than Group LF $(p<0.05)$. Complete motor block was obtained within 20 minutes in every patient in both groups (Bromage 3). Motor block developed faster and lasted longer with the hyperbaric bupivacaine $(\mathrm{p}<0.05)$ (Table 3).

Hypotension and bradycardia were more common in the $\mathrm{BF}$ group. In addition, nausea was noticed more frequently in the BF group $(\mathrm{p}<0.05)$ (Table 4).

Other side effects such as headache, backache, itching and vomiting in the groups were similar.

It was observed that the requirement of intraoperative ephedrine was higher in Group BF and the time to first analgesic requirement was longer in Group BF $(p>0.05)$ (Table 5).

\section{Discussion}

In our study, sensory block levels required for cesarean section were achieved in both groups, and it was observed that the hemodynamic stability with levobupivacaine was better maintained.

In most of the studies where the same doses of levobupivacaine and bupivacaine were investigated, sensory and motor block characteristics were found to be similar. Glaser et al. compared $3.5 \mathrm{ml} \mathrm{[16]} \mathrm{and} \mathrm{Fattorini} \mathrm{et} \mathrm{al.}$

Table 2. Characteristics of sensory blocks.

\begin{tabular}{lcc}
\hline & & Groups \\
\cline { 2 - 3 } & Group LF (n=30) & Group BF (n=30) \\
\hline Time to onset of sensory block (min) & $2 \pm 0.37$ & $1.46 \pm 0.50$ \\
& $2(1-3)$ & $1(1-2)$ \\
Time for the sensory block to reach T10 (min) & $4.6 \pm 1.47$ & $5.46 \pm 1.07$ \\
& $5(2-7)$ & $13.16 \pm 2.57$ \\
Time for the sensory block to reach maximum level (min) & $11.96 \pm 1.97^{*}$ & $13.50(9-20)$ \\
& $12(8-15)$ & $3.14 \pm 0.56$ \\
Maximum sensory level (T dermatome) & $3.56 \pm 0.64^{*}$ & $3(2-4)$ \\
Time to regression by two dermatomes for the sensory block (min) & $4(2-4)$ & $76.16 \pm 13.86$ \\
& $71.43 \pm 12.96^{*}$ & $75(65-80)$ \\
Regression time to $\mathrm{T}_{12}$ for the sensory block (min) & $73(63-78)$ & $162.33 \pm 10.56$ \\
\end{tabular}

Data for sensory block level expressed as mean dermatome and median (interquartile range). Continuous data expressed as mean \pm SD. $p<0.05=$ statistically significant. ${ }^{*} \mathrm{p}<0.05$.

Table 3. Characteristics of motor blocks.

\begin{tabular}{lcc}
\hline & & Groups \\
\cline { 2 - 3 } & Group LF (n=30) & Group BF (n=30) \\
\hline Time to onset of motor block (min) & $4.1 \pm 0.88^{*}$ & $2.36 \pm 0.61$ \\
& $4(2-6)$ & $2(2-4)$ \\
Time to maximum motor block level (min) & $11.36 \pm 2.35^{*}$ & $6.13 \pm 1.56$ \\
& $12(5-15)$ & $6(4-10)$ \\
Regression time for the motor block (min) & $99 \pm 9.13^{*}$ & $132.66 \pm 7.15$ \\
\end{tabular}

Data are expressed as mean $\pm \mathrm{SD}$ and median (interquartile range). $\mathrm{p}<0.05=$ statistically significant. ${ }^{*} \mathrm{p}<0.05$. 
Table 4. Side effects observed in the groups.

\begin{tabular}{lcc}
\hline & \multicolumn{2}{c}{ Groups } \\
\cline { 2 - 3 } & Group LF $(\mathrm{n}=30)$ & Group BF $(\mathrm{n}=30)$ \\
\hline Hypotension (n) & $5^{*}$ & 11 \\
Bradycardia (n) & $2^{*}$ & 9 \\
Headache (n) & 7 & 6 \\
Backache (n) & 1 & 1 \\
Nausea (n) & $3^{*}$ & 10 \\
Vomiting (n) & 1 & 1 \\
Itching (n) & 1 & 1 \\
\hline
\end{tabular}

Data are expressed as number. ${ }^{*} \mathrm{p}<0.05=$ statistically significant.

Table 5. Amounts of ephedrine administered and time to first analgesic requirement in the groups.

\begin{tabular}{lcc}
\hline & \multicolumn{2}{c}{ Groups } \\
\cline { 2 - 3 } & $\begin{array}{c}\text { Group LF } \\
(\mathrm{n}=30)\end{array}$ & $\begin{array}{c}\text { Group BF } \\
(\mathrm{n}=30)\end{array}$ \\
\hline Ephedrine use (mg) & $8.21 \pm 2.48^{*}$ & $15.2 \pm 3.26$ \\
Time to first analgesic requirement (min) & $145.5 \pm 11^{*}$ & $161.3 \pm 12.5$ \\
\hline
\end{tabular}

Data are expressed as mean $\pm \mathrm{SD}, \mathrm{p}<0.05=$ statistically significant.

compared $3 \mathrm{ml}$ [17] 0.5\% isobaric bupivacaine with levobupivacaine, and both reported that there was no significant difference in terms of maximum distribution, and durations of sensory and motor block. In a study on urological surgery, it has been reported that $2.5 \mathrm{ml} 0.5 \%$ isobaric levobupivacaine and $2.5 \mathrm{ml} 0.5 \%$ hyperbaric bupivacaine had equal effects in spinal anesthesia and that the time to onset of sensory block and duration of sensory block were similar [18]. In a dose-effect study comparing racemic bupivacaine and levobupivacaine in patients undergoing urological surgery, Lee et al. [19] reported that $2.6 \mathrm{ml} 0.5 \%$ racemic bupivacaine and levobupivacaine have a nearly equivalent clinic profile and hemodynamic effects. In another study conducted in volunteers, spinal anesthesia was administered in doses of $4,8,12 \mathrm{mg}$ by using hyperbaric spinal levobupivacaine and racemic bupivacaine, sensory and motor block characteristics in different doses were compared. It has been reported that in the same doses hyperbaric levobupivacaine and racemic bupivacaine had the same effects [20].

We observed in our study that maximum sensory block level in bupivacaine group was higher and development of motor block was faster and lasted longer. The results of our study are contradictory to those from the studies mentioned above. However, similar results have been also reported by Gautier et al. [21] during spinal anesthesia for caesarean delivery. They compared the same doses of levobupivacaine and bupivacaine, and reported that while adequate anesthesia was maintained in the $97 \%$ of the patients in the bupivacaine group, this rate was $80 \%$ in the levobupivacaine group, and duration of motor block and analgesia was shorter in the levobupivacaine. In our study also, sensory and motor block durations were found to be shorter in the levobupivacaine group. The effects of baricite on the block characteristisc have been contradictory in literature: while some studies that report the difference in baricite does not affect block charecteristics [22] on the one hand, there are also studies reporting that motor block develops and disappears faster when hyperbaric solutions are used [23] on the other hand. Therefore we cannot ascribe the difference of sensory and motor block between the two groups in our study to the difference of baricite only.

Fentanyl is widely used to increase the duration of analgesia without increasing the duration of motor block, and to reduce required local anesthetic dosage [24]. Choi et al. [25] reported that the combination of $8 \mathrm{mg}$ bupivacaine and $10 \mu \mathrm{g}$ fentanyl is as efficient as $12 \mathrm{mg}$ of hyperbaric bupivacaine. The number of studies on the effects of the combination of intrathecal levobupivacainefentanyl [26] is limited, and the data on appropriate dosages for caesarean sections are inadequate. Prior to our research, we undertook a pilot study using the different dosages given in the literature, to determine the dosages to be used in our study.

Hypotension is the most common complication in the spinal anesthesia [27]. It is known that besides its effects on the mother, it causes acidosis by altering uteroplacental perfusion. Administering hydration using crystalloid or colloid before the spinal anesthesia has proved insufficient [28]. Titti et al. [29] reported that the rate of occurrence of hypotension was $62 \%$ in elective cesarean operations in which they administrated spinal anesthesia with $2.5 \mathrm{ml} 0.5 \%$ bupivacaine. In our study, the incidence of hypotension with bupivacaine was found to be $36.6 \%$. We believe that this difference in our results might be related to the fact that we had decreased the dose of local anesthetic and added fentanyl. The incidence of hypotension was significantly reduced to $16.6 \%$ in the doses we used in the levobupivacaine group. Fattorini et al. [17] reported that although they did not observe a significant difference in the sensory and motor block characteristics of levobupivacaine and bupivacaine among 60 patients who undergo major orthopedic surgery, they did not find severe hypotension and better cardiovascular stability was provided in the levobupivacaine group, Parpaglioni et al. [30] investigated minimum local anesthetic dose in caesarean sections, and they reported that in the levobupivacaine group, in which they administered similar doses with our study, the incidence of hypotension decreased significantly. Gunusen et al. [31] have compaired different doses of levobupivacaine-fentanyl combination in cesa- 
rean section and reported that $10 \mathrm{mg}$ levobupivacaine with $10 \mu \mathrm{g}$ fentanyl combination provides $100 \%$ effective anesthesia but the incidance of hypotension was high. The higher hypotension rates reported by Gunusen et al. may be related to the difference in the definition of hypotension between the studies. While they considered $20 \%$ decline of systolic blood pressure from baseline values as hypotension, we accepted the $25 \%$ decline as hypotension.

That the rate given as $38.5 \%$ in levobupivacaine group seems far higher than our results might have stemmed from the fact that while they regard a $20 \%$ decrease in blood pressure from the baseline value as hypotension, we consider a $25 \%$ decrease as hypotension.

Glasser et al. [11] in line with our study, reported that levobupivacaine, compared with bupivacaine, causes less bradycardia, and that reduces arterial pressure less.

In regional anesthesia for caesarean sections, nausea and vomiting can occur due to a few factors. The most important reason is that cerebral blood flow decreases in consequence of hypotension. Other reasons are related to the level where block reaches. It may as well occur because of an increase in the block level, or because of the fact that structures related to peritonea stretch during the operation due to an inadequate block level. We can explain the reduced incidence of nausea occurred in the levobupivacaine group with the fact that the doses we administered developed adequate blocks, and caused less hypotension.

\section{Conclusion}

We conclude that single-shot spinal anesthesia performed with both local anesthetic drugs provides fast and effective induction of surgical anesthesia for elective cesarean section. Since motor block time is shorter, and side effects like hypotension, bradycardia and nausea are less, the combination of levobupivacaine + fentanyl can be a good alternative in cesarean sections.

\section{REFERENCES}

[1] H. Blomqvist and A. Nilsson, "Is Glucose-Free Bupivacaine Isobaric or Hypobaric?" Regional Anesthesia and Pain Medicine, Vol. 14, No. 4, 1989, pp. 195-198.

[2] M. G. Richardson and R. N. Wissler, "Densities of Dextrose-Free İntrathecal Local Anesthetics, Opioids, and Combinations Measured at 37 Degrees C," Anesthesia \& Analgesia, Vol. 84, No. 1, 1997, pp. 95-99.

[3] M. G. Richardson and R. N. Wissler, "Densities of Lumbar Cerebrospinal Fluid in Pregnant and Nonpregnant Humans," Anesthesiology, Vol. 85, No. 2, 1996, pp. 326-330. doi:10.1097/00000542-199608000-00014

[4] A. C. Lui, T. Z. Polis and N. J. Cicutti, "Densities of Cerebrospinal Fluid and Spinal Anaesthetic Solutions in
Surgical Patients at Body Temperature," Canadian Journal of Anesthesia, Vol. 45, No. 4, 1998, pp. 297-303. doi:10.1007/BF03012018

[5] M. R. Logan, J. H. McClure and J. A. Wildsmith, "Plain Bupivacaine: An Unpredictable Spinal Anaesthetic Agent," British Journal of Anaesthesia, Vol. 58, No. 3, 1986, pp. 292-296. doi:10.1093/bja/58.3.292

[6] M. P. Vercauteren, H. C. Copp, V. L. Hoffmann, V. Sadien and H. A. Adriaensen, "Small-Dose Hyperbaric versus Plain Bupivacaine during Spinal Anesthesia for Cesarean Section," Anesthesia \& Analgesia, Vol. 86, No. 5, 1998, pp. 989-993.

[7] S. P. Hallworth, R. Fernando, M. O. Columb and G. M. Stocks, "The Effect of Posture and Baricity on the Spread of Intrathecal Bupivacaine for Elective Cesarean Delivery," Anesthesia \& Analgesia, Vol. 100, No. 4, 2005, pp. 11591165. doi:10.1213/01.ANE.0000149548.88029.A2

[8] P. M. S. Dobson and L. D. Caldicott and S. P. Gerrish, "Delayed Asystole during Spinal Anaesthesia for Transurethral Resection of the Prostate," European Journal of Anaesthesiology, Vol. 10, No. 1, 1993, pp. 41-43.

[9] F. Kohler, J. F. Sorensen and H. S. Helbo-Hansen, "Effect of Delayed Supine Positioning after İnduction of Spinal Anaesthesia for Caesarean Section," Acta Anaesthesiologica Scandinavica, Vol. 46, No. 4, 2002, pp. 441446. doi:10.1034/j.1399-6576.2002.460419.x

[10] T. J. Scull and F. Carli, "Cardiac Arrest after Caesarean Section under Subarachnoid Block," British Journal of Anaesthesia, Vol. 77, No. 2, 1996, pp. 274-276. doi: $10.1093 / \mathrm{bja} / 77.2 .274$

[11] R. Z. Lovstad, G. Granhus and S. Hetland, "Bradycardia and Asystolic Cardiac Arrest during Spinal Anaesthesia: A Report of Five Cases," Acta Anaesthesiologica Scandinavica, Vol. 44, No. 1, 2000, pp. 48-52. doi:10.1034/j.1399-6576.2000.440109.x

[12] H. M. R. Povey, J. Jacobsen and J. Westergaard-Nielsen, "Subaracnoid Analgesia with Hyperbaric 0.5\% Bupivacaine: Effect of a 60-Min Period of Sitting," Acta Anaesthesiologica Scandinavica, Vol. 33, No. 4, 1989, pp. 295-297. doi:10.1111/j.1399-6576.1989.tb02911.x

[13] Y. Huang, M. Pryor, L. Mather and B. Veering, "Cardiovascular and Central Nervous System Effects of Intravenous Levobupivacaine and Bupivacaine in Sheep," Anesthesia \& Analgesia, Vol. 86, No. 4, 1998, pp. 797 804.

[14] S. Morrison, J. Dominguez, P. Frascarolo and S. Reiz, "A Comparison of the Electrocardiographic Cardiotoxic Effects of Racemic Bupivacaine, and Ropivacaine in Anesthetized Swine," Anesthesia \& Analgesia, Vol. 90, No. 6 , 2000, pp. 1308-1314. doi:10.1097/00000539-200006000-00009

[15] G. A. McLeod, "Density of Spinal Anaesthetic Solutions of Bupivacaine, Levobupivacaine, and Ropivacaine with and without Dextrose," British Journal of Anaesthesia, Vol. 92, No. 4, 2004, pp. 547-551. doi:10.1093/bja/aeh094

[16] C. Glaser, P. Marhofer, G. Zimpfer, M. T. Heinz, C. Sitzwohl, S. Kapral and I. Schintler, "Levobupivacaine 
versus Racemic Bupivacaine for Spinal Anesthesia," Anesthesia \& Analgesia, Vol. 94, No. 1, 2002, pp. 194-198.

[17] F. Fattorini, Z. Ricci, A. Rocco, R. Romano, M. A. Pascarella and G. Pinto, "Levobupivacaine versus Racemic Bupivacaine for Spinal Anaesthesia in Orthopaedic Major Surgery," Minerva Anestesiologica, Vol. 72, No. 7-8, 2006, pp. 637-644.

[18] O. Vanna, L. Chumsang and S. Thongmee, "Levobupivacaine and Bupivacaine in Spinal Anesthesia for Trannsurethral Endoscopic Surgery," Journal of The Medical Association of Thailand, Vol. 89, No. 8, 2006, pp. 11331139.

[19] Y. Y. Lee, K. Muchhal and C. K. Chan, "Levobupivacaine versus Racemic Bupivacaine in Spinal Anesthesia for Urological Surgery," Anaesthesia and Intensive Care, Vol. 31, No. 6, 2003, pp. 637-641.

[20] E. A. Alley, D. J. Kopacz, S. B. McDonald and S. S. Liu, "Hyperbaric Spinal Levobupivacaine: A Comparison to Racemic Bupivacaine in Volunteers," Anesthesia \& Analgesia, Vol. 94, No. 1, 2002, pp. 188-193.

[21] P. Gautier, M. De Kock, L. Huberty, T. Demir, M. Izydorczic and B. Vanderick, "Comparison of the Effects of Intrathecal Ropivacaine, Levobupivacaine and Bupivacaine for Caesarean Section," British Journal of Anaesthesia, Vol. 91, No. 5, 2003, pp. 684-689. doi:10.1093/bja/aeg251

[22] M. G. Richardson, H. V. Collins and R. N. Wissler, "Intrathecal Hypobaric versus Hyperbaric Bupivacaine with Morphine for Cesarean Section," Anesthesia \& Analgesia, Vol. 87, No. 2, 1998, pp. 336-340.

[23] P. J. Sarvela, P. M. Halonen and K. T. Korttila, "Comparison of $9 \mathrm{mg}$ of Intrathecal Plain and Hyperbaric Bupivacaine both with Fentanyl for Cesarean Delivery," Anesthesia \& Analgesia, Vol. 89, No. 5, 1999, pp. 12571262. doi:10.1213/00000539-199911000-00033

[24] B. Ben-David, E. Solomon, H. Levin, H. Admoni and Z. Goldik, "Intrathecal Fentanyl with Small-Dose Dilute Bupivacaine Better Anaesthesia without Prolonging Recovery," Anesthesia \& Analgesia, Vol. 85, No. 3, 1997 , pp. 560-565. doi:10.1213/00000539-199709000-00014
[25] D. H. Choi, H. J. Ahn and M. H. Kim, "BupivacaineSparing Effect of Fentanyl in Spinal Anesthesia for Cesarean Delivery," Regional Anesthesia and Pain Medicine, Vol. 25, No. 3, 2000, pp. 240-245. doi:10.1016/S1098-7339(00)90005-1

[26] Y. Y. Lee, K. Muchhal, C. K. Chan and A. S. Cheung, "Levobupivacaine and Fentanyl for Spinal Anaesthesia: A Randomized Trial," European Journal of Anaesthesiology, Vol. 22, No. 12, 2005, pp. 899-903. doi:10.1017/S0265021505001523

[27] P. A. Hall, A. Bennett, M. P. Wilkes and M. Lewis, "Spinal Anaesthesia for Caeserean Section: Comparison of Infusions of Phenylephrine and Ephedrine," British Journal of Anaesthesia, Vol. 73, No. 4, 1994, pp. 471-474. doi: $10.1093 / \mathrm{bja} / 73.4 .471$

[28] T. Yorozu, H. Morisaki, M. Kondoh, M. Zenfuku and T. Shigematsu, "Comparative Effect of 6\% Hidroxyethylstarch (Containing 1\% Dextrose) and Lactated Ringer's Solution for Cesarean Section under Spinal Anesthesia," Journal of Anesthesia, Vol. 16, No. 3, 2002, pp. 203-206. doi:10.1007/s005400200025

[29] T. Thoren, B. Holmström, N. Rawal, J. Schollin, S. Lindeberg and G. Skepp, "Sequential Combined Spinal Epidural Block versus Spinal Block for Cesarean Section: Effects on Maternal Hypotension and Neurobehavioral Function of the New-Born," Anesthesia \& Analgesia, Vol. 78, No. 6, 1994, pp. 1087-1092.

[30] R. Parpaglioni, M. G. Frigo, A. Lemma, M. Sebastiani, G. Barbati and D. Celleno, "Minimum Local Anaesthetic Dose (MLAD) of Intrathecal Levobupivacaine and Ropivacaine for Caesarean Section," Anaesthesia, Vol. 61, No. 2, 2006, pp. 110-115. doi:10.1111/j.1365-2044.2005.04380.x

[31] I. Gunusen, S. Karaman, A. Sargin and V. Firat, "A Randomized Comparison of Different Doses of Intrathecal Levobupivacaine Combined with Fentanyl for Elective Cesarean Section: Prospective, Double-Blinded Study," Journal of Anesthesia, Vol. 25, No. 2, 2011, pp. 205-212. doi:10.1007/s00540-011-1097-4 